\title{
Healthcare Systems \& its Challenges in Pakistan
}

\author{
Muhammad Faisal Hashami \\ Health Department, Basic Health Unit: Bhainwala, District: Sheikhupura, Punjab-Pakistan \\ Corresponding author: faisal_hashami@yahoo.com
}

Received: 22-08-2019

Revised: $19-01-2020$

Accepted: 24-02-2020

\begin{abstract}
This paper shows the multiple challenges in Healthcare Systems' Programme and its weaknesses and also gives some recommendations to improve it. Healthcare system plays very important role in the development of the country. If a country wants to make progress in all fields of life, it should provide the health atmosphere to its citizens and it is only then possible when it is increased by manpower system. Pakistan is an underdeveloped country and it stands 65th position among 102 developing countries. It has totally taken inherited Healthcare system from British side in 1947and now this Healthcare system consists of private and public sector. The private sector serves nearly $70 \%$ of population and $30 \%$ by public sector (Papanek, 2019). According to the constitution of provisional health of Pakistan, it is the government responsibility to provide the health facility to its citizens. Healthcare Services are delivered through a three-tiered namely; (Primary, secondary and territory Healthcare system). In Primary Healthcare services only Basic Health Units (BHUs) and Rural Health Centers (RHCs) are included. And in Secondary Healthcare Services Tehsil Head Quarters (THQs) and District Head Quarters (DHQs) are included. And Tertiary Healthcare hospital is an individual system.
\end{abstract}

Keywords: Healthcare System; Health Policies; Health challenges \& Programs in Pakistan

Pakistan is an underdeveloped country and has become an independent country in $14^{\text {th }}$ August 1947. At that time, it has no health policy. So at that time, it inherited its health care system from British side, which was comprised on three tiers:

1. Primary Healthcare system

2. Secondary Healthcare system

3. Tertiary Healthcare system

\section{Primary Healthcare system}

Primary Healthcare system is the first level of Healthcare system, where mostly patients have their initial interaction with Curative and Preventive Healthcare Services.

\section{(i) Basic Health Units \& Rural Health Centers}

Basic Health Units (BHUs) are serviced its services at Union Council level up to 25,000 Population. It provides preventive, curative and referral services to the patients.

Maternal and Child Health $(\mathrm{MCH})$ services are also provided at Basic Health Units with the sport of Lady Health Workers (LHWs). According to Primary \& Secondary Health Care Department (2016) that "BHUs also provide clinical, logistical and managerial support to Lady Health Workers (LHWs)". According to Abbasi (2016) that "Now at this time in Pakistan total 5464 Basic Health Units (BHUs) are working" that help to support and make progress the working of RHC and THQ.

Rural Health Centers (RHCs) are providing preventive, curative, diagnostic and referral services to the patients 
up to 100,000 people. Along this it also support to BHUs, LHWs and MCH Centers to promote and make progress their work. Now at this time in Pakistan total 675 Rural Health Units (RHUs) and 733 mother and child health centers and allied medical professionals are working (Abbasi, 2016).

\section{Secondary Healthcare system}

Secondary Healthcare system is the second level of Healthcare system that is directly concerned with the provision of technical, therapeutic and diagnostic services to the patients. It is considered first referral level at district and tehsil. Specialist consultation doctors fall into system and patients are admitted in the hospital in this category.

\section{Tehsil Head Quarters \& District Head Quarters}

Tehsil Head Quarters (THQs) consist on 40-60 beds and also serving around about 0.5 to 1 Million people. THQs play supportive role to provide Basic Diagnostic Services, Emergency Services and Newborn Care Services to the patients, especially for those that are referred from RHCs, BHU and Lady Health Workers' side. District Head Quarters (DHQs) also serve 1-3 million population and they are located at district level. They provide all kind of medical services (like promotive, preventive, curative, diagnostics, inpatient and referral services). All DHQs provide referral care services to those patients, which were referred by BHUs, RHCs and Tehsil Head Quarters.

\section{Tertiary Healthcare}

Tertiary Healthcare Hospitals are for more specialized inpatient care (Keane \& Richmond, 1993). And all these services are provided to the inpatients, which were referred from primary or secondary healthcare centers. And now at this time, "Pakistan has 1,142 hospitals". (Mashhadi et al. 2016).

\section{CHALLENGES IN HEALTHCARE SYSTEM OF PAKISTAN}

Healthcare System has been facing many challenges like the shortage of trained human and financial resources with Poor Governance, political interference and lack of accountability for poor performance etc. In Pakistan, "Health system has been designed by politicians, while it has been implemented by the health professionals on the ground level" (Shaikh \& Rabbani, 2004). Especially the access and stability of the country's rural population regarding health services is a major problem "because of severe shortage of healthcare professionals and inadequate allocation of funds for Primary Healthcare sector" (Punjani et al. 2014). Reliable Health Information Management system is not available at primary and secondary levels though we can improve the health services. Another place Shaikh \& Rabbani (2004) illustrates the same point of view that "lack of medical research and technology at national level is one of reason to deliver sub-standard services". In Pakistan, Mostly Health Policies are developed without planning, so they can't give fruitful results at the mention time.

\section{HEALTH POLICIES OF PAKISTAN}

Pakistan announced its First formal National Health Policy in 1990. In this policy, it is clearly declared that the health expenditures will be up to $5 \%$ of GNI and second priority will be given to clean water and family planning to improve health. Khan \& Heuvel (2005) showed in their study that "Pakistan' Second National Health Policy was introduce in 1997, which basic aim was "Health for All (HFA)" and in this policy special attention was given to HIV/ AIDS, road traffic accidents, violence, tuberculosis, cancer, diabetes and mental health diseases". Pakistan formulated third National Health Policy in 2001, which was again based on "Health for All (HFA)" approach. At that time, ten key areas identified reducing communicable disease, addressing inadequacies in primary/secondary healthcare, promoting gender equity, correcting rural/ urban discrepancy in health sector and improvements in drug sector etc. (Akram et al. 1961). Only draft policy was prepared in 2010 but was not approved due to their disbursement process. Federal and Provincial Governments agree on common Nation Health Vision (2016-2025). Wirtz et al. (2017) also reflect the same point of view that "Vision statement is to improve health of all Pakistanis particularly women and children through affordable universal access to quality Healthcare Services, delivered through responsive health system". 


\section{HEALTH PROGRAMS IN PAKISTAN}

Pakistan is an economically poor country, which is trying to achieve its indicators in the regions. However there are some preventive and curative programs, which ensure to the public health timely. "National Program for Family Planning \& Primary Healthcare was launched in 1994" (Wazir et al. 2013). From these programs, around about 80 million people of rural and urban areas are got benefits. "Expanded Programme of Immunization (EPI) was launched in Pakistan in 1978" (Rafi et al. 1995). Its main objectives were to reduce mortality and morbidity by offering timely immunization services. Malaria Control Programme was started in Pakistan since 1950. Rasheed et al. (2013) and it strengthened the same point of view that "Malaria control program was initiated in Pakistan in 1950s". It has been passed through several evolutionary phases. In 1975, Malaria Control Strategy was adopted with the aim of provincial commitment to Execution and our Govt. has been successful execute it in 1977 at provinces level with communicable disease control program. The Federal Ministry of Pakistan has launched National AIDS Prevention and Control Program (NACP) in 1987 with the objective to diagnosis all those cases that came to hospitals.

In 2001, the first National Strategy Framework was developed with collaboration of provincial programs, after that $2^{\text {nd }}$ National Strategy Framework and then $3^{\text {rd }}$ Framework was developed. So that its services of treatment could be quality wise improved. And after that National AIDS Prevention and Control Program (NACP) shift on community level with the help of UN agencies. National TB Control Program is one of the Public Health Programs, which is integrated with Primary Health Care (PHC) system. It is a basically Millennium Developmental Goal' target, which was achieved in 2015 with the objectives "to reduce the prevalence of MDR-TB among the patients who have never received any tuberculosis treatment by at least $5 \%$ per year by 2020" (Khan et al. 2006). Drug Abuse Control Program was started by Ministry of Narcotics Control in 201014 with the objective of "drug free Pakistan". There are numerous other programs are run at National level and Provincial level like; National Program for the Prevention and Control of Blindness, Cancer Treatment
Program, Tobacco Control Cell, National Nutrition Program and National Maternal, Newborn and Child Health Program, School Health Program etc.

\section{WEAKNESSES IN HEALTH POLICIES OF PAKISTAN}

Pakistani Health Policies are designed by the politicians, who have no knowledge about the field, while the policy has been implemented by the health professionals on the ground level then it can't give positive responses instead of the wastage of resources. In our beloved country mostly policies are focused on Curative Healthcare Programme instead of Preventive Healthcare Programme. In Curative Healthcare Programme, our main motive is to promote the services for the patients such as: laboratories, ambulances and modern equipment. But on the other hand, in Preventive Healthcare Programme, we mentally promote our nation for the future so that they can defend their self from the diseases. The developed country is the best example because they have focused on the preventive Healthcare Programme instead of the Curative Healthcare Programme in their countries.

In Pakistan, we should follow the developed countries strategies as they have follow in the health field irrespective of religious, cultural values, social dimension and economic differences etc.The Health policies of the country can determine to prevent from disease rather than covering the same cultural and environmental values. In which, All vertical programs are implemented at primary Healthcare facilities level but these programs are administered and run by Federal Government (Magnussen et al. 2004). It disrupts the BHU and district level because they do not involve in the planning of programs. There is no system to step up, estimate and use data for district level assessment and policy reforms. As a result data is not presented to Federal Ministry for feedback and evaluation of vertical programs (Fisman \& Gatti, 2002).

\section{CONCLUSION}

Primary Healthcare system of Pakistan is facing numerous problems. Decentralization provides an opportunity to bring basic changes in Primary Healthcare 
system to make effective and more efficient to the masses. The basic purpose of the Primary Healthcare Sector is to restore the effective system from federal to the district level. Punjani et al. (2014) concluded that "Primary Healthcare system includes building blocks such as leadership, service delivery, technology, health workforce, healthcare finance and research". In which monitoring and evaluation play an important role to get quality services and chase target at the time.

\section{Recommendations}

In the light of findings, the following recommendations are proposed as key recommendations to improve Healthcare sector of Pakistan.

* It would be highly beneficial, if policy making power is decentralized and delegated to districts level because they can take a better and realistic sense or point of view for resolving the issue on daily basis.

* All shareholders should be involved in planning, decision and implementation of any Programs at all level. So that the progress and stability of program can ensure.

* Policy makers and its implementers should be constructed better monitoring and evaluation tools to get valuable and unbiased feedback form the system.

* Pakistan is $3^{\text {rd }}$ one country, where only one doctor is available for twelve hundred people. So, all doctors should be performed their duties as consultants in the hospitals and professors in the medical colleges instead of any another jobs.

* The administrative duty should be assigned to only those members, who are aware of administration and human behavior knowledge because in administration, an administrator has to face a lot of difficulties in the form of human behavior, which varies for man to man at the same time.

* The Govt. should organized different training at provincial and district level for the Doctors \&paramedical staff so that their abilities could be enhanced and they can perform their duty diligently and smoothly.
* It is recommended that our Govt. should increase health care system budget, and to proper check and balance on quackery, to exchange of human knowledge and resource with developed countries, to promote health education among the common people so that decrease the social evils like that; illiteracy rate, over population, corruption etc.

\section{REFERENCES}

Papanek, G.F. 2019. Pakistan's development: Social goals and private incentives. Harvard University Press.

Primary \& Secondary Health Care Department. (n.d.). Retrieved October 26, 2016, from http://www.pshealth.punjab.gov.pk/ Services.aspx

Pakistan economic survey. 2015. Health and Nutrition.

Keane, A. and Richmond, T. 1993. Tertiary nurse practitioners Image: The Journal of Nursing Scholarship, 25(4): 281-284.

Mashhadi, S.F., Hamid, S., Roshan, R. and Fawad, A. 2016. Healthcare in Pakistan-a systems perspective. Pakistan Armed Forces Medical Journal, 66(1): 136-42.

Shaikh, B.T. and Rabbani, F. 2004. The district health system: a challenge that remains.

Khan, M.M. and Heuvel, W.V. 2005. Description and content analysis of the National Health Policy of Pakistan. Asia Pacific Journal of Public Health, Accepted pending revisions.

Punjani, N.S., Shams, S. and Bhanji, S.M. 2014. Analysis of health care delivery systems: Pakistan versus United States. International Journal of Endorsing Health Science Research, 2(1): 38-41.

Akram, M. and Khan, F.J. 1961. Health care services and government spending in Pakistan. Working Papers $\mathcal{E}$ Research Reports, 2007, 2007-32.

Wirtz, V.J., Hogerzeil, H.V., Gray, A.L., Bigdeli, M., de Joncheere, C.P., Ewen, M.A. ... and Möller, H. 2017. Essential Medicines for Universal Health Coverage. The Lancet, 389(10067): 403-476.

Wazir, M.S., Shaikh, B.T. and Ahmed, A. 2013. National program for family planning and primary health care Pakistan: a SWOT analysis. Reproductive Health, 10(1): 60.

Rafi, S., Shah, I.A., Rao, M.H. and Billoo, A.G. 1995. Expanded Programme for Immunization in Karachi. Journal-Pakistan Medical Association, 45: 34-34.

Rasheed, S.B., Butlin, R.K. and Boots, M. 2013. A review of dengue as an emerging disease in Pakistan. Public Health, 127(1): 11-17.

Khan, J.A., Irfan, M., Zaki, A., Beg, M., Hussain, S.F. and Rizvi, N. 2006. Knowledge, attitude and misconceptions regarding 
tuberculosis in Pakistani patients. Journal of Pakistan Medical Association, 56(5): 211.

Magnussen, L., Ehiri, J. and Jolly, P. 2004. Comprehensive versus selective primary health care: lessons for global health policy. Health Affairs, 23(3): 167-176.
Fisman, R. and Gatti, R. 2002. Decentralization and corruption: Evidence from US federal transfer programs. Public Choice, 113(1-2): 25-35. 
